\title{
Rakebot: a robotic rake for mixing paddy in sun drying
}

Ertie Abana, Meljiflor Pacion, Roxanne Sordilla, Daniel Montaner, Dennis Agpaoa, Rryma Mae Allam Interior Design and Information Technology Education, University of Saint Louis, Philippines

\begin{tabular}{l} 
Article Info \\
\hline Article history: \\
Received Sep 16, 2018 \\
Revised Nov 17, 2018 \\
Accepted Feb 22, 2019 \\
\hline
\end{tabular}

\section{Keywords:}

Agricultural robots

Microcontrollers

Robot control

Mobile application

\begin{abstract}
Sun drying is a conventional drying method of paddy commonly used in Asia. During the process, grains are mixed and turned continuously using a rake to maintain good quality. For this reason, a robotic rake or Rakebot was developed in this study to properly mix the grains during sun drying. Rakebot is manually controlled using a mobile application through Bluetooth connection but can also move automatically using the previous movements that were recorded on the first used. It was developed using a microcontroller that gives directions to the motors based on the received instructions from the mobile application. The recorded movements are saved in a memory card by means of a memory card module connected to the microcontroller. The objective measures showed that the Rakebot ensures simultaneous reduction of the moisture content of paddy.
\end{abstract}

Copyright (C) 2019 Institute of Advanced Engineering and Science. All rights reserved.

Corresponding Author:

Ertie Abana,

Interior Design and Information Technology Education

University of Saint Louis,

Mabini St., Ugac Sur, Tuguegarao City, Cagayan, Philippines.

Email: ertie04@gmail.com

\section{INTRODUCTION}

In the field of agriculture, farmers are now utilizing robots to significantly increase productivity. These robots are very important to improve both crop yield and quality while reducing tasks performed under harsh conditions [1]. For example, robotic tractors [2-6] for precision agriculture improved energy use and reduced the atmospheric pollution emission; robotic weed control systems [7-8] reduced agriculture's current dependency on herbicides; phenotyping robots [9] easily collects the labor-intensive data required to perform experiments on crops; and fertilizer dispensing robot [10-11] saves labor time and get better results with minimum amount of fertilizers. However, most of the robots utilized in farming are mostly used in the preplanting and growth stage of agricultural products which leave behind the development of postproduction robots.

Postproduction activities in farming include drying, storing and milling. According to International Rice Research Institute (IRRI), drying is the most important process after harvesting because grain quality will be reduced if there are delays in drying as well as incomplete or ineffective drying. Among the various ways of drying grains, sun drying is the most common means especially in tropical countries [12-13] because it only requires little investment and is eco-friendly. However, using this method under hostile climate conditions may lead to severe losses in the quantity and quality of the rice [13]. Moreover, sun drying is labor-intensive wherein grains should be turned or stirred repeatedly to maintain good quality. Another problem with this method is workers continuous mixing of the grain often results in fissured grain that reduces the quality of the paddy.

Keeping in mind the advantages of using robots in agriculture, a robotic rake was developed in this study. The robot will solve the great demand for human labor in sun drying of paddy as well as the risk of having fissures on the grains. The robotic rake is a one of its kind postproduction robot for mixing of grains in sun drying of paddy. A mobile application is used to control the movement of the Rakebot but it has the 
ability to learn the prior movements so that it will not be controlled anymore in the next usage. Moreover, a well-designed rake is attached to the robot to ensure simultaneous moisture reduction.

The development of Rakebot will greatly benefit farmers as they will not anymore endure the heat when they are sun drying their grains. Grain traders will also benefit significantly by moving their workers on other tasks while the Rakebot is doing the mixing of grains.

\section{PROPOSED METHOD}

The main purpose of the Rakebot is to mix the grains using a mobile app. The movements of the Rakebot are recorded while the user is using it. When the grains need to be raked again, the user can just press the play button on the mobile app allowing the robot to move automatically using the recorded movements.

Figure 1 shows the flow of commands through the Rakebot in which major parts are represented by the boxes with its relationship represented by lines. A mobile phone is needed to interact with the machine via an application to send signals to the microcontroller using the Bluetooth module as a medium. The microcontroller is the brain of the whole system and, along with the relay, is the one responsible for triggering the motors to make the robot move. The memory card is where the prior movements are being stored.

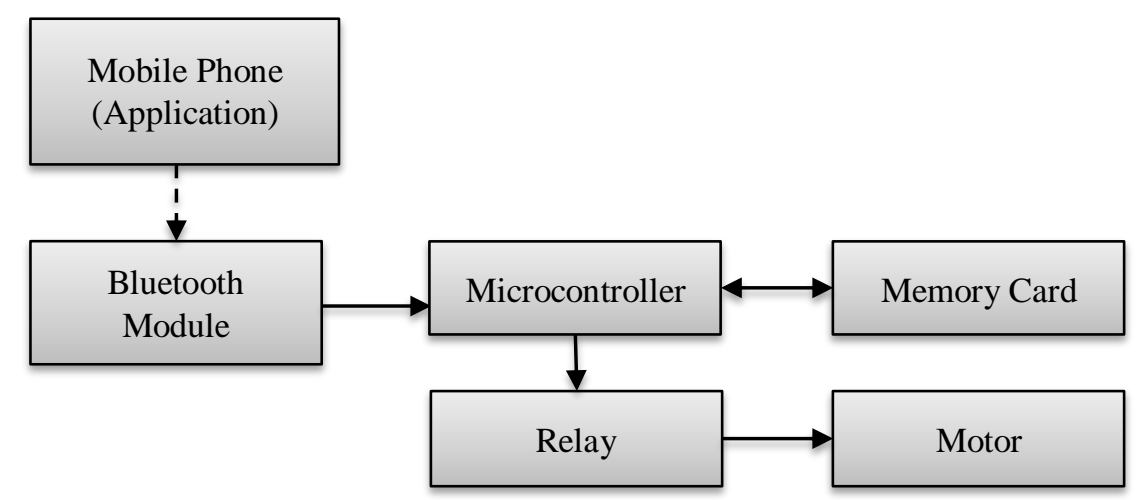

Figure 1. The Block Diagram of Rakebot

\subsection{Project Design and Specification}

Figure 2 shows the connection of the components used in the development of the Rakebot. The Bluetooth module which is connected to the microcontroller acts as the bridge between the Rakebot and the mobile phone. The microcontroller waits for the command of the user once the connection has been established. When the user presses a movement on the mobile app the microcontroller triggers the relay so that power will flow on the motors allowing the Rakebot to move. The Rakebot is powered by a $12 \mathrm{~V}$ battery that is charged by a solar panel.

\subsection{Arduino Uno Microcontroller}

The Arduino Uno is a microcontroller board having 20 digital input/output pins, of which only 12 are used for the Rakebot. Electronic projects and embedded systems [14] are usually developed using this general purpose microcontroller [15] because of ease of wiring [16]. It is programmed using Arduino Integrated Development Environment software [17-20].

The Arduino Uno served as the brain of the Rakebot because it processed the interaction between the robot and the user. It holds the code that enables the Bluetooth module, relay, and memory card module to work. The pins RX, TX, $+5 \mathrm{~V}$, and GND of the Bluetooth module are connected to the TX, RX, $+5 \mathrm{~V}$, and GND pins of the Arduino Uno microcontroller, respectively. The pins MISO, MOSI, CLK, and CS of the memory card module are also connected to the Arduino on pins 12, 11, 13, and 4, respectively. Moreover, the IN1, IN2, IN3, IN4, VCC and GND pins of the 4-channel relay module are connected to pins $9,8,7,6,+5 \mathrm{~V}$, and GND of the Arduino Uno, respectively. 


\subsection{Radiator Fan Motor}

The motor used for the movements of the Rakebot is a heavy duty radiator fan motor having rotations per minute (RPM) of up to 2000. This motor operates at $12 \mathrm{~V}$ and is capable of handling heavy loads.

In the development of the Rakebot, two motors were used which served as the left and right wheel. It is connected to the common terminals of the relay wherein movement depends on what motor is rotating. Forward movement means the two motors are rotating. On the other hand, a left turn or a right turn means only one motor is rotating.

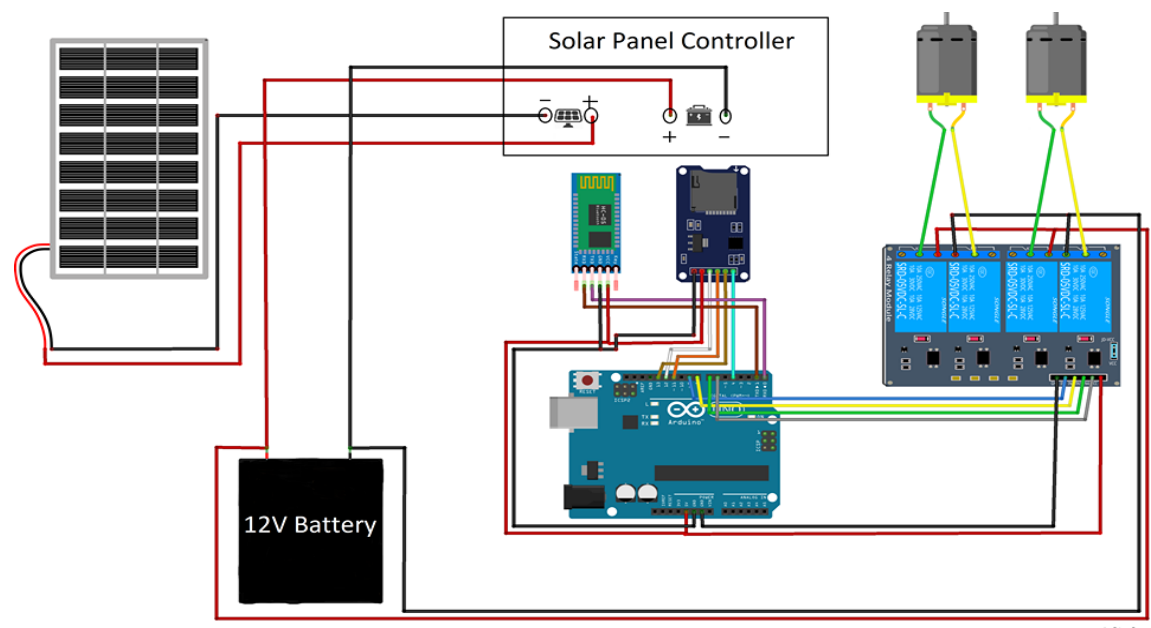

Figure 2. The Schematic Diagram of the Rakebot

\subsection{Mobile App Building Platform}

The Rakebot movement depends on the button pressed by the user in the mobile application. When a button is pressed, a command is wirelessly sent to the microcontroller via Bluetooth module.

The mobile application used in controlling the Rakebot was developed using App Inventor. This programming platform was introduced by Google for the public but Massachusetts Institute of Technology (MIT) is now maintaining it. App Inventor is a free web application that is basically used for creating Android Apps using a browser. It is very simple and no prior programming experience [21] is done when creating an app. It is merely arranging blocks together to make the app working. It can be easily integrated into Arduino microcontrollers which makes it a common programming platform for mobile app controlled robots.

\section{RAKEBOT}

The Rakebot shown in Figure 3 is made of galvanized steel case painted with rust prevention paint to prevent rust and corrosion when exposed to oxygen and water.

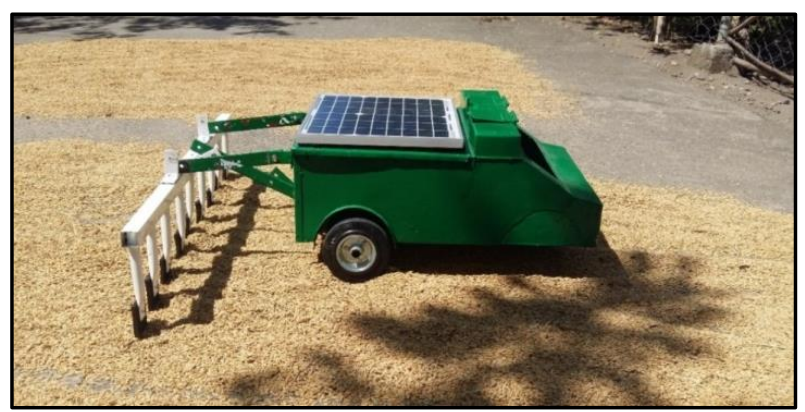

Figure 3. The working prototype of the Rakebot 


\subsection{The Rakebot}

It is green in color to easily distinguish the machine at long distances while being restful on the eyes. The solar panel is located on top of the Rakebot like other solar-powered devices to permit optimal operation [22]. The charge controller is also positioned on top of the Rakebot with a hinged cover to easily view the total charge of the battery. The control devices were placed on top of a small platform made of galvanized steel inside the Rakebot. The front wheels of the Rakebot are caster wheels that enable easy rolling movement. For the back wheel, a pair of rubber wheels was used which are connected to the motors that allow movement of the Rakebot. The rake at the back of the Rakebot is made of lightweight aluminum with rubber sheet at its tip to avoid harming the grains. It has gaps in-between to assure that the mixing of the grains is uniform for simultaneous moisture content reduction.

\subsection{Mobile App Controller}

The design of the graphical user interface (GUI) of the Rakebot's controller shown in Figure 4 follows a customer-centered design [23] wherein users are expected to run the application with no training. The current status of the robot is shown below the name of the app. The status of the Rakebot are "Connected" when connection is established with the Rakebot; "Not Connected" when the Rakebot is not yet connected with the mobile app; "Recording" when the movements are being recorded; "Forward" when it is moving forward; "Left" when it is turning on the left; and "Right" when it is turning on the right.

Buttons are used in connecting, controlling and storing data to the Rakebot. The Bluetooth button opens a list of devices that the smartphone can be paired up with. The Rakebot must be paired with the smartphone where the mobile app is installed to control it. The play button is used to instruct the Rakebot to repeat its recorded movements while the reset button is used to redo the recorded movements. The stop button, on the other hand, will command the system to stop recording the movements. The machine automatically stops once the movement buttons are let go.

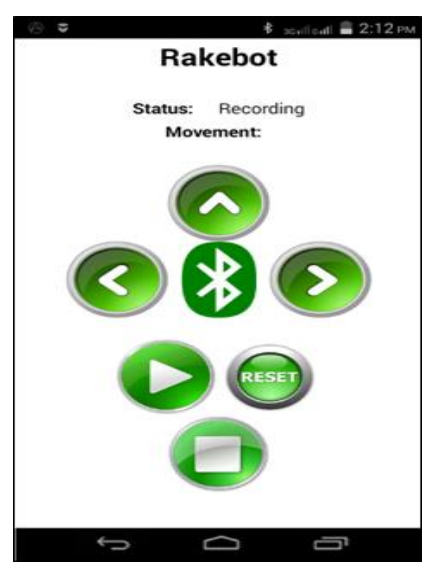

Figure 4. GUI of the mobile application

The play button serves a significant role towards the achievement of one of the goals of the study which is to reduce labor requirement. When the previous movements are already recorded, a user will place the robot in the initial area where the raking will start. Then, the user needs to connect the mobile phone to the Rakebot and press the play button. No human intervention is needed when the Rakebot start to rake the paddy which means that the user can proceed with another task. Also, the use of the Rakebot would allow grain traders to hire only a few workers as the Rakebot can do the raking repeatedly and independently.

\section{RESULTS AND DISCUSSION}

Raking the paddy continuously prevents the grains from overexposure to the strongest rays of the sun which cause fissures on grains. This should be done properly to ensure that heat is distributed on the laid rice grains and have nearly identical moisture content. The Rakebot was tested to mix newly harvest paddy laid in a pavement for sun drying. The moisture content from the different area of the laid paddy is measured after mixing using the Rakebot. This test was done for three different samples of 25 kilograms of $\mathrm{C} 18$ rice using Rakebot. 
It is evident from Table 1 that the moisture content of grains from the different area of the laid paddy are almost identical which means that Rakebot was able to mix the grains properly maintaining an ideal thin layer. The well-placed rake of the Rakebot maintains $2-4 \mathrm{~cm}$ layers of grains following the recommendation of IRRI.

The result is an indication that Rakebot was able to ensure simultaneous reduction of the moisture content of paddy which is important so that fissuring will not happen and grains will be of good quality. Moreover, the nearly identical moisture content gathered after the third mixing of the grains is in the optimum moisture content [24] recommended for milling.

Table 1. The Moisture Content of Rice Grains Mixed Using Rakebot

\begin{tabular}{ccccccc}
\hline \multirow{2}{*}{ Sample } & Mixing & \multicolumn{5}{c}{ Moisture Content (\%) } \\
\cline { 3 - 6 } 1 & First & 18.3 & 17.9 & 17.8 & 18.1 & 18.4 \\
& Second & 16.1 & 16.6 & 16.4 & 16.3 & 16.2 \\
& Third & 13.9 & 14.0 & 13.8 & 14.1 & 14.2 \\
2 & First & 20.5 & 20.6 & 20.2 & 19.9 & 20.1 \\
& Second & 17.5 & 17.7 & 18.1 & 17.6 & 17.9 \\
& Third & 13.3 & 13.5 & 13.4 & 13.9 & 13.6 \\
3 & First & 18.4 & 18.4 & 18.3 & 18.5 & 17.9 \\
& Second & 16.3 & 16.5 & 16.6 & 16.3 & 16.2 \\
& Third & 13.6 & 13.9 & 14.0 & 13.7 & 13.8 \\
\hline
\end{tabular}

A good quality paddy which is free of fissures is needed to produce good quality milled rice. One manifestation of good quality milled rice is having a high milling recovery. The Milling Recovery (\%) according to IRRI is computed by dividing the weight of milled rice recovered by the weight of the paddy sample.

$$
\text { Milling recovery }(\%)=\frac{\text { Weight of milled rice }}{\text { Weight of paddy sample }} \times 100
$$

Using the Rakebot, three samples of $25 \mathrm{~kg}$ of rice are mix every 30 minutes until the $14 \%$ moisture content was achieved. The rice is then milled and the milling recovery was computed. The weight of the paddy after sun drying and weight of milled rice are presented in Table 2.

Table 2. The Weight of the Samples

\begin{tabular}{ccc}
\hline Sample & Paddy $(\mathrm{kg})$ & Milled Rice $(\mathrm{kg})$ \\
\hline 1 & 24.1 & 15.2 \\
2 & 24.2 & 15.7 \\
3 & 23.8 & 14.8 \\
\hline
\end{tabular}

The three samples yielded a milling recovery of $63.07 \%, 64.88 \%$, and $62.18 \%$, respectively. The milling was done using a compact rice mill wherein according to IRRI the use of this milling process should yield more than $60 \%$ milling recovery. The acceptable milling recovery computed from using the Rakebot in mixing the paddy during sun drying manifest its gentleness in mixing the grains. The rake with attached rubber on the tip of the Rakebot made sure that there are no fissures on grains that can result to lower milling recovery [25].

\section{CONCLUSION}

The special features and functions of Rakebot have helped improve the sun drying process. These features include the mobile app controller, the automatic functioning, and the well-designed rake. The mobile app controller will allow workers to stay in the shade while raking to escape the heat of the sun. The automatic functioning of Rakebot when a prior movement is already recorded sufficiently reduces labor requirements. Above all, the well-designed rake has ensured simultaneous reduction of moisture content and avoided the risks of having fissures on grains.

The invention should not be considered limited to what has been disclosed in the study. Rather, the claims of the study imply that further improvements can be achieved while still adhering to the intent of the invention. The device can be multifunctional in the way that it could substitute a grain spreader and/or a 
grain collector. Also, the robot should have a method of alerting the user when the grains have achieved the optimal moisture content to prevent over-drying.

\section{ACKNOWLEDGEMENTS}

This work was supported by the University Research Center and the Computer Engineering Program of the University of Saint Louis.

\section{REFERENCES}

[1] Bechar A, Vigneault C. Agricultural robots for field operations: Concepts and components. Biosystems Engineering. 2016; 149: 94-111.

[2] Gonzalez-de-Soto M, Emmi L, Garcia I, Gonzalez-de-Santos P. Reducing fuel consumption in weed and pest control using robotic tractors. Computers and electronics in agriculture. 2015; 114: 96-113.

[3] Gonzalez-de-Soto M, Emmi L, Benavides C, Garcia I, Gonzalez-de-Santos P. Reducing air pollution with hybridpowered robotic tractors for precision agriculture. Biosystems Engineering. 2016; 143: 79-94.

[4] Johnson DA, Naffin DJ, Puhalla JS, Sanchez J, Wellington CK. Development and implementation of a team of robotic tractors for autonomous peat moss harvesting. Journal of Field Robotics. 2009; 26(6-7): 549-71.

[5] Noguchi N, Barawid Jr OC. Robot farming system using multiple robot tractors in Japan agriculture. IFAC Proceedings Volumes. 2011; 44(1): 633-7.

[6] Yang L, Noguchi N. Development of a wheel-type robot tractor and its utilization. In Proceedings of the 19th World Congress of the IFAC. Cape Town, South Africa, 2014; 11571-11576.

[7] Slaughter DC, Giles DK, Downey D. Autonomous robotic weed control systems: A review. Computers and electronics in agriculture. 2008; 61(1): 63-78.

[8] Bakker T, van Asselt K, Bontsema J, Müller J, van Straten G. An autonomous weeding robot for organic farming. InField and Service Robotics. Springer, Berlin, Heidelberg, 2006; 579-590.

[9] Shah DS, Tang L. Development of an Autonomous Indoor Phenotyping Robot. ASABE Annual International Meeting. Orlando. 2016: 1-12.

[10] Singh N, Shaligram A. D. NPK Measurement in Soil and Automatic Soil Fertilizer Dispensing Robot. International Journal of Engineering Research \& Technology. 2014; 3(7): 635-7.

[11] Shivaprasad BS, Ravishankara MN, Shoba BN. Design and implementation of seeding and fertilizing agriculture robot. International Journal of Application or Innovation in Engineering \& Management (IJAIEM). 2014; 3(6): 251-5.

[12] Imoudu PB, Olufayo AA. The effect of sun-drying on milling yield and quality of rice. Bioresource Technology. 2000; 74(3): 267-269.

[13] El-Sebaii AA, Shalaby SM. Solar drying of agricultural products: A review. Renewable and Sustainable Energy Reviews. 2012; 16(1): 37-43.

[14] Gogineni VR, Matcha K. Real Time domestic power consumption monitoring using wireless sensor networks. International Journal of Electrical and Computer Engineering (IJECE). 2015; 5(4): 685-694.

[15] Gunawan TS, Yaldi IR, Kartiwi M, Mansor H. Performance Evaluation of Smart Home System using Internet of Things. International Journal of Electrical and Computer Engineering (IJECE). 2018; 8(1): 400-411.

[16] Latupapua H, Wahab A, Latupapua AI, Alaydrus M. Wireless Sensor Network Design for Earthquake's and Landslide's Early Warnings. Indonesian Journal of Electrical Engineering and Computer Science. 2018; 11(2): 437-445.

[17] Abana E, Bulauitan KH, Vicente RK, Rafael M, Flores JB. Electronic Glove: a Teaching Aid for the Hearing Impaired. International Journal of Electrical and Computer Engineering (IJECE). 2018; 8(4): 2290-2298.

[18] Çakir A, Badri A. Fire Tracking and Suppression Mobile Robot-Design and Construction. Indonesian Journal of Electrical Engineering and Computer Science. 2017; 5(1): 159-65.

[19] Susanto D, Seminar KB, Sukoco H, Liyantono L. Parallel Processing Implementation on Weather Monitoring System for Agriculture. Indonesian Journal of Electrical Engineering and Computer Science. 2017; 6(3): 682-7.

[20] Shajahan AH, Anand A. Data acquisition and control using Arduino-Android platform: Smart plug. International Conference on Energy Efficient Technologies for Sustainability (ICEETS), 2013; 241-244).

[21] Hsu YC, Rice K, Dawley L. Empowering educators with Google's Android App Inventor: An online workshop in mobile app design. British Journal of Educational Technology. 2012; 43(1): E1-5.

[22] Leccese F, Leonowicz Z. Intelligent wireless street lighting system. IEEE International Conference on Environment and Electrical Engineering (EEEIC). Rome. 2012: 958-961.

[23] Holtzblatt K. Customer-centered design for mobile applications. Personal and Ubiquitous Computing. 2005; 9(4): 227-237.

[24] Janier JB, Maidin MB. Paddy moisture content detector. Journal of Applied Sciences. 2011; 11(7): 1476-1478.

[25] Guisse R. Post-Harvest Losses of Rice (Oriza Spp) From Harvesting to Milling: A Case Study in Besease and Nobewam in the Ejisu Juabeng District in the Ashanti Region of Ghana. Master of Science in Post-Harvest Physiology Thesis. Kwame Nkrumah University of Science and Technology, Kumasi, Ghana; 2010. 